\title{
The End(s) of Language in Brian Friel's Translations and Enda Walsh's Disco Pigs and misterman
}

\author{
Christian Schmitt-Kilb
}

\begin{abstract}
In my analysis of Brian Friel's modern classic drama Translations (1980) and Enda Walsh's plays Disco Pigs (1996) and misterman (2001), I have chosen not to consider these in order to point towards structural or plot parallels between the plays, nor to emphasise the interdependency of the two authors; I am instead concerned with their differences, particularly with differences in their approach to language as a medium of (often failed) communication. I would like to suggest that it is possible to read the plays as signs of their times within an Irish context. At the time of its first staging in 1980, the popularity of Friel's play was largely due to the fact that it was seen as a "tough-minded play about the brutal actualities of cultural power" (Kiberd 1995: 618-619), power exerted by the English upon the Irish. The negotiations of the difficulties of intercultural communication in a hierarchic or even colonial situation in this work require a sense of social consciousness which is altogether absent in Walsh's plays. Here, ca. twenty years later, we are confronted with monadic subjects (even though they are two of them in Disco Pigs) who are fundamentally juxtaposed to the idea of society as such and consequently run amok right from their births. There are "utopian moments" in Friel and Walsh involving the reestablishment of communication.
\end{abstract}

\section{Introduction}

Before dealing with the subject matter of my topic, it is important to point out that what follows should not be mistaken for a fully-fledged research paper. It should rather be understood as an attempt to delineate certain questions and issues which arose out of classroom discussions about the plays. Thus for the sake of polarisation and stimulation of discussion, it juxtaposes in a rather woodcut-like fashion positions which would have to be regarded as simplifications in a "purely" literary critical or cultural studies discourse. I am focusing on isolated aspects of the plays only without delving into the intricacies and subtleties of critical analysis in order to provide food for thought and point to some accessible further reading for those dealing with the plays in education rather than 
contribute substantially to the critical debate. This is the base on which the reader should form his or her opinion about the weaknesses and strengths of the essay.

It may seem somewhat unusual to compare a discussion of two Enda Walsh plays, Disco Pigs (1996) and misterman (2001), with a classic of modern Irish Drama, Brian Friel's play Translations (1980), but I hope that in the course of the essay the reasons for this pairing become clear. My main concern is the treatment of language in Enda Walsh's plays, both language as a means of communication which sometimes works and more often does not, and language as one of the touchstones of a culture and as the main medium of a society's internal negotiations about identity. Reading Walsh against the backdrop of Brian Friel's Translation, I want to suggest that a shift has occurred within the approximately twenty years between Friel's and Walsh's plays, a shift which is indicated foremost by the differing treatment of a culture's language problem but which ultimately touches upon issues of cultural politics and of history.

As the title of Friel's play suggests, Translations deals with language, and as it is a play, it necessarily deals in language as well. Friel himself has emphasised that fact by limiting the thematic scope of the play to "language and only language" (Friel in Klein 2007: 90), but his own position has been met with criticism in this respect. Although language is of course one of the dominant issues, the play is written as a "history play"1 set in the nineteenth century. Moreover, it needs to be read against the backdrop of the modern phase of the Troubles, which were already in their second decade when the play was written.

\section{Language in Brian Friel's Translations}

Translations is set in Donegal, in a stereotypical Irish village in the thirties of the nineteenth century. It tells the story of a small community on the brink of irrevocable change. Focusing on a small hedge school and its teachers and students, its main theme is the loss of the Irish language and the mapping of Ireland by the Anglicising Ordnance Survey. Most of the action takes place in the home of learned Hedge School master Hugh O'Donnell, where, in accordance with British law, Catholic pupils are taught classics and mathematics. As the play begins, O'Donnell's school has already lost at least two of its pupils to the brewing political unrest as British troops and engineers have begun to conduct an ordinance survey intended to map the landscape for military intelligence and standardise the Gaelic place-names in the King's English. O'Donnell's two sons, Manus and Owen, are bound for opposing destinies. Manus, lame since childhood, lives at home and dreams of marrying the wild and uncouth Maire, a student at the school. Owen has left home and is a successful businessman, but

\footnotetext{
${ }^{1}$ Klein (2007: 86) argues that a number of Irish plays written in the eighties, amongst them Friel's Translations, may be called "history plays in every sense of the word" as they "probe the recent past for its mental and material impact on the present."
} 
he returns in the opening scenes working as a translator for two British officers involved in co-ordinating the ordinance survey.

One of these officers, Lieutenant Yolland, is entranced with the romance of the land he has come to alter with language and law. The other is a more pragmatic captain, there simply to do his job. Personal and political conflicts are intertwined as the action begins to unfold. Characters are forced to confront questions about themselves in which the very words they speak are central to understanding their origins and their futures. The translation of place-names is explicitly related to a transformation of the landscape itself. This trauma will affect these people on multiple levels, and though by the close of the action the story has not been resolved, the audience is made painfully aware of the change which has begun to disturb the lines of communication between peoples, countries, and languages. ${ }^{2}$

In one of the play's most important "bilingual" scenes, Yolland and Maire share an intimate moment after having fled from a dance. They express their love for each other without understanding the words either is speaking. Willing the audience to suspend disbelief, they are to assume that Yolland speaks English and Maire Gaelic while both parts are written and spoken in English:

\section{Yolland.}

: (Indicating himself) George.

(Maire nods:Yes-Yes.Then:-)

Maire: Lieutenant George.

Yolland.

: Don't call me that. I never think of myself as Lieutenant.

Maire: What-what?

Yolland.

: Sorry-sorry? (He points to himself again.) George. (Maire nods:Yes-yes.Then points to herself.)

Maire: Maire.

Yolland.

: Yes, I know you're Maire. Of course I know you're Maire. I mean I've been watching you night and day for the past -

Maire: (Eagerly) What-what?

Yolland.

: (Points) Maire. (Points) George. (Points both) Maire and George. (Maire nods:Yes-yes-yes.) I-I-I-

Maire: Say anything at all. I love the sound of your speech.

Yolland.

: (Eagerly) Sorry-sorry?

\footnotetext{
${ }^{2}$ Friel was quite liberal with historical facts, as many critics have pointed out. The Ordinance Survey, the dominant image of the play for cultural suppression and the imposition of foreign norms on native traditions, has been shown by e.g. Joep Leerssen to be "a major contribution to the cultural nationalism of later decades, in that it equated the very land itself with a Gaelic past and a Gaelic-speaking peasantry, thus canonizing the Gaelic tradition as the very bedrock of modern Ireland." Quoted in Klein 2007: 90.
} 
(In acute frustration he looks around, hoping for some inspiration that will provide him with communicative means.)...

Maire tries Latin:

Maire.

: Tu es centurio in - in - in exercitu Britannico -

Yolland.

: Yes-yes? Go on - go on - go on - say anything at all - I love the sound of your speech.

(Friel 1996: 427)

This scene illustrates Friel's trick of having the entire play performed in English (with the odd Latin sentence) while expressing linguistic and cognitive distance between characters who are supposed to be speaking Irish (and Latin and Greek), and those who only speak English. (The irony that Yolland takes Latin for Irish serves various purposes: It highlights the naiveté of the English Lieutenant, the supposed educational superiority of the Hedge Schools and, most importantly in the context of the play, it symbolises how the English and the English language have managed to incorporate the language of the "colonizer" to such an extent that the speakers don't even recognize it.) Throughout the first half, tentative relationships develop despite the distances between the characters. Following this scene, the play becomes darker, reflecting the historical reality of the events which followed (and of which the play was speaking metaphorically in the present) in which resolution becomes impossible. This moment is the pivot on which the drama turns.

"But for the loss of the Irish language, there would be little discussion about identity in the republic", writes the historian of Ireland, J.J. Lee (1989: 662) in 1989. He may be exaggerating to a point, but in general, many of the debates surrounding Irish cultural identity have been triggered by the language issue. When Friel wrote the play in the late seventies, it was perceived not only as a play engaging in the writing or rewriting of an important phase in Irish history. In the year of its first production in 1980, its concern with nationality was immediately read in the context of contemporary Northern Irish politics. Too much so, with the result that the qualities of the play as a play were shifted into the background and political commentary replaced drama criticism to a large extent.

With appropriate critical and temporal distance, Christopher Murray praises "the device of having two languages on stage although only one (English) is spoken" as it "brilliantly exposes two areas of experience, two cultures" (Murray 2000: 211). Towards the close of the play, Máire repeats her wish to learn the English language and asks Hugh to teach her. Hugh is sceptical about the possibilities of communication between cultures in the first place: "I will provide you with the available words and the available grammar. But will that help you to interpret between privacies?" (Friel 1996: 446) The scepticism about the possibilities of communication runs very deeply, especially in a colonial context. In the play, Dan O'Connell and Maire both assume that the use of English will help them to progress towards their respective national and personal dreams. 
But even though Maire may be seen as a representative of the young and modern Ireland who no longer allows herself to be hindered by the weight of myth and tradition, it must also be mentioned that Maire's desire to speak English shall soon be enforced by law throughout the National Schools in Ireland.

One of Friel's major intellectual inputs, in some instances even sources, for the play was George Steiner's After Babel, in which Steiner not only stresses the virtual impossibility of intercultural understanding but also reflects upon the possibility of the alienation of a nation's language from a historical situation. Both concerns are echoed in Friel's play. When the romantic Yolland, who is in love with Maire, expresses his desire to learn Irish, Hugh reminds him "that a civilisation can be imprisoned in a linguistic contour which no longer matches the landscape of ... fact" (ibid. 419). This may be true even in the case of Irish: "A rich language. A rich literature. [... ] Certain cultures expend on their vocabularies and syntax acquisitive energies and ostentations entirely lacking in their material lives." (ibid. 418) Hugh's seemingly contradictory advice to Maire and Yolland regarding their plans to learn the language of the other shows that Hugh is conscious of the complexities inherent in the language debate.

Friel's version of Steiner, Translations, is first and foremost about the conflict between Ireland and England, exemplified through the conflict between the Irish and the English languages in a political and historical context. As a result of its monolingual form, it "translates what is by the play's own terms untranslatable; its supple and eloquent English speaks the lost and hidden language of Irish" (Grene 1999: 45). It can and has frequently been read as a text in which the empire writes back, an Irish playwright using the English language to commemorate the Irish culture of which the English colonists have deprived him. But there is also a counter-voice, a less self-assured voice, to that dominant discourse, which is expressed by Hugh in the last scene of the play. Here he reflects upon the advantages and disadvantages of clinging to tradition in the face of change. It is "images of the past embodied in language", not the facts as such, which shape us, he insists, and goes on to explain that "we must never cease renewing those images" (Friel 1996: 445) unless we want to risk to fossilize. "We must learn to make them our own. We must make them our new home." (ibid. 444) The acknowledgement that language (and thus culture) are in a state of flux may be read as cultural defeatism on the part of Hugh, but it may also be seen as a sign that there is some middle ground between the two polar opposites, between (the) English as the colonizer and (the) Irish as the colonized, and that the tilling of that ground is important for the future of both.

\section{The End(s) of Language in Enda Walsh's Disco Pigs and misterman}

\subsection{Disco Pigs}

According to George Steiner, there is a strong element of interpretation and translation involved in all communication, not only between languages 
but also within one native language. "Inside or between languages, human communication equals translation" (Steiner 1975: 47). WhileFriel's Translations highlights "between language"-difficulties in understanding, Enda Walsh, in several of his plays from the Mid-1990s onwards, focuses on the impossibility of communication "within". This is not just a change of theme, I think. More than that, it points to the fact that the ideas and commonplace aspects associated with Ireland in parts of the population only twenty years ago have given way to something else, something not easily definable. "It seems fairly clear", writes Christopher Murray, "that in Ireland in the 1990s it is not possible to invoke the nation in the same terms as obtained even a generation ago" (Murray 2000: 245). One of the major differences seems to be a fundamental change in the perception of contemporary society and, following that, a changed sense of what politics is all about, how it affects the individual, and how the individual can make a difference (or not).

This change is comparable to theatre developments in England, where the state-of-the-nation play in the nineties - often epic in scope, political in subject matter, spanning decades - has been replaced by a brutal, direct and often provocative new realism. Irish writers such as Walsh have created their own versions of "In-yer-face"-Theatre, a term coined by critic Aleks Sierz (2001). "In-yer-face", according to the New Oxford English Dictionary (1998), is something "blatantly aggressive or provocative", to which the Collins English Dictionary adds "confrontational". It implies the invasion of personal space by being forced to see, hear or experience something close up, and the theatre which is labelled thus tries to put audiences in such a situation. One of the play's major means to reflect the tensions and fragmentations within society is the extremism of its confrontational language, a strategy which helps to underline the impression that language is ultimately a means of failing communication.

As opposed to twenty years ago, any kind of imaginary unity no longer seems to be possible, even ex negativo. The frightening but also perversely comforting image of the English is no longer there, an image of the powerful, self-assured Englishmen naively convinced of their superiority. While it was relatively easy to define an Irish identity against that image, now the rift, at least on stage, runs right through Irish society. With Pig and Runt, the main protagonists of Disco Pigs (1996), Walsh has created a strong image of isolation within, an isolation not of choice but one of fate.

Pig and Runt, two 17-year old inhabitants of Pork Sitty (Cork City), have almost completely isolated themselves from the rest of society by engaging in highly asocial behaviour and by speaking an artificial language which only the two of them fully understand. Always together and always on the look-out for alcohol and the next victim, their symbiotic relationship has grown more and more hermetic with an increasing number of mutually committed crimes. This set-up does not allow for social criticism on the part of the characters, criticism of a society which turns human beings into monads. Quite the opposite: Pig and Runt are radicals not due to any kind of opposition but by pushing to an extreme the mechanisms of isolation at work in the modern world. Enda Walsh 
demonstrates how the communicative character of language may turn into its opposite and only serve to increase the sense of isolation.

The play starts with the birth of Darren and Sinead, who simultaneously "bounce inta a whirl of grey happiness" (Walsh 1996: 6). One day playing animals on a farm they turn themselves into Pig and Runt, and from that moment onwards they act out their self-chosen roles.

So we grow up bit at a dime an all dat dime we silen when odders roun. No word or no-ting. An wen ten arrive we squeak a different way den odders. [...] an we looka was happenin an we make a whirl where Pig an Runt jar king an queen! [... ] An Pig look cross at me jus like he look when we were babas an he alla say 'Les kill da town, ya on?' An I alla say - corse I'm on - I'm ja pal, amn't I? An liddle tings we do like robbin an stealin is a good feelin, yes indeedy. An we read dem buuks on howta figh da peeplah ya hate. An Pig own has me... an Runt own have him. But we make a whirl dat no one can live sept us two. Bonny an Clyde, ya seen da movie. (ibid. 15)

Most of the action takes place on their $17^{\text {th }}$ birthday. They do what they always do, drift from one night-club to the next, get drunk and play their favourite "game". Runt chats somebody up and then pretends to be molested by him. Pig interferes and beats the apparent intruder up. Later on, as a birthday present, Pig takes Runt to the sea, "da big blue", "da colour of love". In this rather romantic moment, if this is a suitable term for that kind of drama at all, Runt experiences the beauty of nature for the first time and is so overwhelmed that she, probably for the first time, has doubts about how she leads her life. "I wanna walk inta da sea an neva come back. I wan ta tide to make me outa me an give me someone different." (ibid. 17)

Later on in the same night, they come across the Palace Disco, a posh and expensive night club which is their own personal utopia. They never dreamed of getting in at all, but the trip to the sea, the big blue, helps them, as the password "blue" is the answer to the question: what's the colour of love. Once inside, they are overwhelmed by the shiny chrome and the number of well dressed people. Once let alone, Pig is disturbed by the fact that the other visitors talk and laugh about him, but gets quiet reassuring himself that Runt knows who he is. Runt dreams of a peaceful encounter with another man, but when it actually happens, Pig is convinced that Runt is staging another beating up game for him. She desperately tries to hold him back, but in the end the other guy is dead. This is the starting signal for Runt to run away.

An Runt race good dis time! Mus ged away! No mo all dis play an pain! [...] An it well ovur, drama fans! Jus me! Jus da liddle girl all aloneys! An I wan Pig an I wan for all da buzz an all da disco we do dance but hey ho an wadda ya know I wan fur sumthin else! Sumthin differen! Sumthin differen! Fuckin freedom!! Jus me!! Jus da Runt!! [...] Jus me an da big big colour blue. Dat colour blue! [... ] An I look a da sun crep up on my pal Pork...Cork. [...] An Runt she alone now. But is okay now, is all righ. An I watch... da liddle quack quacks... I look. . . at the ducks as they 
swim in the morning sun... in the great big... watery-shite... that is the river Lee. - Where to? (ibid. 29)

Runt struggles free of the cocoon-like relationship with Pig, turns into Sinead again. Her attempts at socialising have led at the first glance to an even more complete isolation, but the recovery of standard English, already signalled in the scene when they are asked about the password and Runt describes love in standard English, marks a step towards reintegration, or at least it marks the realization that the "sumthin differen" she longs for is to be found only if the basic prerequisite for social intercourse, a common language, is reestablished.

The two Disco Pigs are born into conditions in which, literally right from their birth, they cannot define themselves as social beings. Society simply does not seem to exist aside from as a negative foil, as a fateful conglomeration of equally unconnected others - Thatcher's (in)famous thesis that "There is no such thing as society. There are individual men and women [...] and people must look to themselves first" comes true as a nightmare. Thus even traditional political activism, which is necessarily based on cooperation and the idea of common goals, can only be interpreted in these parameters. An instance of this is when Pig, confronted with Sinn Fein activists in a Pub, asks the "fookin weirdos" whether they "shouldn't be out plantin bombs an beaten up ol ladies." (ibid. 22) For Pig and Runt, the combination of the ideologies of happiness and wilful anarchic isolation indeed ends in that kind of nihilistic asociality, which critics of the postmodern condition have frequently identified

Both Translations and Disco Pigs stage linguistic impossibilities: In both plays, we have representations of languages on stage which we can only understand if it is taken for granted that we do not actually hear what the characters "really" say. In Translations, the audience's willing suspension of disbelief is needed to take English for Gaelic, while watching Disco Pigs we must assume that, were Darren alias Pig and Sinead alias Runt to speak as they themselves describe it, we would understand even less than we actually do. However, whereas the languages represented in Translations have their roots in larger national communities, and the struggle for language only makes sense against a backdrop of these communities and their struggles, the two Disco Pigs explicitly look for a hermetic medium only suitable for themselves - "a whirl were no one can live sept us two" (ibid. 15) - as their ideal. Language politics ceases to be an issue, as wilful isolation has replaced the very idea of a community-based politics.

\section{2 misterman}

misterman, first staged in 1999, is quite a different matter, but again a play which is concerned with short circuit communication and, in a rather ironic way, with Irish identity. Thomas Magill is in his mid-thirties and lives in Inishfree, William Butler Yeats' mythically loaded imaginary Irish Eden. He walks through the town with the mission to clean it of sin and ultimately save it so that he can sit next to God: "Me and God smile and look down on all my good work. It's 
going to be such a beautiful place" (ibid. 42). On the way to his father's grave (which he has decorated with a gravel map of Ireland ("Ireland on the grave with the sea surrounding it") he talks to several inhabitants of the town, but only in his mind, imitating their voices as he goes along. Sometimes, there are fragments of conversation with his mother, but her voice comes from the tape recorder which Thomas carries around with him.

Thomas Magill, unable to establish even the most basic forms of human intercourse, aims to form a working community out of the inhabitants of Inishfree, not realising that he is the most isolated of them all. In his final speech, in which he threatens the whole town with destruction, he claims: "How many times have I listened to you when you had no one to talk to? [...] My heart still holds some regret for what we might have made together." (ibid. 54) These words are addressed to the people taking part in the community dance, although it is not clear if they can hear him at all. They might also be addressed to Edel, a woman or girl he once fancied. The play ends with a recorded dialogue on tape between him and Edel from which we learn that he killed her - the only human being apart from his mother with whom he has really exchanged some words - for refusing to hold hands with him.

Enda Walsh's characters mainly speak in the mode of soliloquy, even if they are not alone on stage. His plays challenge the notion, both formally and thematically, of the possibility of dialogue on stage and in contemporary society. His plays are, in a post-Beckett fashion, as much about language as about the impossibility of meaningful communication. Articulation, which is etymologically the action or process of bridging gaps, of bringing into contact different objects, is here shown to serve quite opposite ends. In fact, Walsh manages to demonstrate how language can augment rather than diminish the mechanisms of isolation at work in the modern world.

Nevertheless, the uneasiness with which one leaves the plays is not only negative, fatalistic or destructive, because the idea of the communicative character of language is still present, if only as remembrance or utopian hope. The monadic individuals in confrontation with (non-existing) communities against which they define themselves are finally seen struggling for the recovery of human ties. Thomas Magill in misterman desperately longs for human bonds which are denied to him, while Sinead alias Runt of Disco Pigs craves for "sumethin differen" symbolised by the "big, big blue". Walsh's plays demonstrate that language on the one hand reflects brutal social realities which further the isolation of the individual but, on the other hand, also contributes to the production of those realities. The result is an original form of non-pedagogical social/language criticism on stage, criticism all the more vital as it does not present itself as such.

\section{Instead of a Conclusion...}

... I would like to emphasise that the plays by Friel and Walsh, although entirely different in scope and conceptual scheme, share an interest in the politics of 
language. This is tangibly so with regard to the reluctant utopinanism, as I would like to call it, inherent in both writers' plays which directly involves power and the question how power is defined: While Translations juxtaposes cultures and languages with a clear understanding about hierarchies and imbalances of power, oppressors and oppressed, and only late in the play relativizes these positions, Walsh may be more rewardingly approached with a Foucaultian, discursive concept of power in mind. Interestingly, in the case of Disco Pigs it is the outsider's language established by Pig and Runt which is first conceived of as a language of power. The exclusiveness of this power results in its speakers not only isolating themselves; it also empowers them to generate their destructive antisocial energy within this isolation. Nevertheless, only when a return into the language community begins to be conceivable by Runt do we catch a glimpse of the extent of desolation, helplessness and despair governing their actions. Thus in both plays, the suggested possibility of a renewal of communication between different parties, involving the veritable learning of language, is the precondition for the reluctant utopianism shining through the dark realities of the plays' presents.

\section{Bibliography}

Friel, Brian (1980): Translations. In: Friel, Brian (1996): Plays 1. London: Faber \& Faber

Grene, Nicholas (1999): The Politics of Irish Drama: Plays in Context from Boucicault to Friel. Cambridge: Cambridge University Press

Kiberd, Declan (1995): Inventing Ireland. The Literature of the Modern Nation. London: Vintage

Klein, Bernhard (2007): On the Uses of History in Recent Irish Writing. Manchester: Manchester University Press

Lee, J. J. (1989): Ireland 1912-1985: Politics and Society. Cambridge: Cambridge University Press

Murray, Christopher (2000): Twentieth-Century Irish Drama: Mirror Up to Nation. Syracuse: Syracuse University Press

Steiner, George (1975): After Babel: Aspects of Language and Translation. Oxford: Oxford University Press

Sierz, Alan (2001): In-yer-face Theatre: British Drama Today. London: Faber \& Faber

Walsh, Enda (1996): Disco Pigs \& Sucking Dublin. London: Nick Hern Books

Walsh, Enda (2001): bedbound / misterman. London: Nick Hern Books 